\title{
HUBUNGAN PENGETAHUAN IBU TENTANG IMUNISASI DASAR DENGAN KECEMASAN DI POSYANDU KELURAHAN PASAR BARU KECAMATAN SEI TUALANG RASO TAHUN 2019
}

\author{
Sumiatik $^{1}$, Lolita Nugraeny ${ }^{2}$, Dharmawati $^{3}$ \\ Universitas Haji Sumatera Utara, Indonesia
}

\begin{tabular}{|c|c|}
\hline Article Info & ABSTRACT \\
\hline Article history: & $\begin{array}{l}\text { Immunization is a way to actively increase a person's immunity against an } \\
\text { antigen, so that if one day he is exposed to a similar antigen the disease does }\end{array}$ \\
\hline Received Sep 28, 2019 & not occur. Immunization is important to prevent dangerous diseases. The \\
\hline Revised Sep 29, 2020 & purpose of this study was to determine the relationship between maternal \\
\hline Accepted Sep 30, 2020 & knowledge about basic immunization and anxiety in Posyandu, Pasar Baru, \\
\hline & rrelation which is the research of the relationship between two variables. \\
\hline Keywords: & $\begin{array}{l}\text { all mothers who have children under five in Pasar Baru Kelurahan. Sei } \\
\text { Tualang Raso. With a population of } 36 \text { people. Data analysis using the C- }\end{array}$ \\
\hline Knowledge & Square Test. Results of the study were conducted to 25 majority of \\
\hline Anxiety & respondents with Less Knowledge as many as 15 people (42\%). Frequency \\
\hline Basic Immunization & of Basic Immunization with Anxiety as many as 21 people (58\%). C-Square \\
\hline & Test Results Showing a (0.05) obtained X2 $=0.04 \mathrm{p}$ (sig) $0.138<0.05$. Based \\
\hline & on the results of this study it can be concluded that there is a Relationship \\
\hline & $\begin{array}{l}\text { between mother's knowledge about basic immunization with anxiety. So it is } \\
\text { suggested to health workers to provide information to the public about basic }\end{array}$ \\
\hline & \\
\hline
\end{tabular}

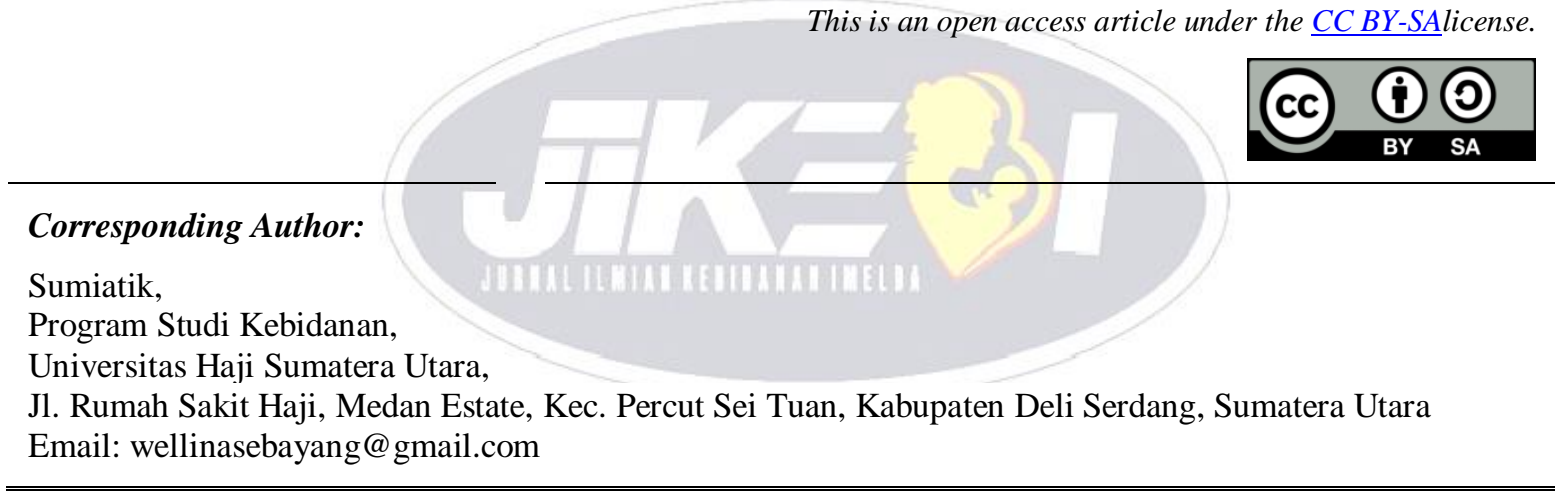

\section{INTRODUCTION}

Imunisasi merupakan usaha pemberian kekebalan pada bayi dan anak dengan memasukkan vaksin kedalam tubuh agar tubuh membuat zat anti untuk mencegah terhadap penyakit tersebut (Hidayat, 2012). Imunisasi adalah suatu cara untuk meningkatkan kekebalan tubuh seseorang secara aktif terhadap suatu antigen, sehingga bila kelak ia terpajang pada antigen yang serupa tidak terjadi penyakit. Imunisasi penting untuk mencegah penyakit berbahaya, salah satunya adalah Imunisasi DPT (Diptheria, Pertusis, Tetanus). Kebanyakan anak menderita panas setelah mendapat imunisasi DPT, tetapi itu adalah hal yang wajar, namun seringkali ibu-ibu tegang, cemas dan khawatir (Tecyya, 2014).

Program imunisasi merupakan sebuah keberhasilan dalam mencegah penyakit infeksi. Hal ini terbukti dari menurunnya kejadian penyakit menular di Amerika Serikat dan negara lain sejak pertengahan abad ke-20. Di Indonesia sejak tahun 1990, cakupan Imunisasi dasar telah mencapai lebih dari 95\% (Ranuh, 2010). Di Indonesia terdapat imunisasi yang diwajibkan oleh pemerintah sebagaimana juga yang di wajibkan WHO seperti imunisasi BCG, DPT, Hepatitis, Campak dan Polio. Menurut data yang didapat dari Direktorat Jendral Pengendalian Penyakit dan Penyehatan Lingkungan Departemen Kesehatan Indonesia pada tanggal 
27 Mei 2011 menunjukan angka kecakupan imunisasi ditahun 2010 adalah campak 89,5\%, DPT-3 90,4\% dan Hepatitis B-3 mencapai 91\%. Dari data yang ada, terlihat angka cakupan imunisasi dasar Indonesia sudah cukup tinggi, namun pada beberapa daerah masih ditemukan angka cakupan dibawah Standar Nasional (Depkes RI, 2011).

Jumlah kasus cakupan imunisasi DPT/HB1-campak di Provinsi Jawa Timur pada tahun 2012 di dapatkan kabupaten ponorogo sebesar 93\%. Berdasarkan data P2PL Dinas Kesehatan Kabupaten Ponorogo pada bulan januari sampai dengan november 2013 jumlah sasaran bayi sebesar 12.383, sedangkan bayi yang berusia dibawah 5 bulan sebesar 1.583. Sedangkan cakupan imunisasi sebesar 90,9\% (P2P1, 2013).

Kecemasan adalah menunjukan reaksi terhadap bahaya yang memperingatkan orang "dari dalam “ secara naluri, bahwa ada bahaya dan orang yang bersangkutan mungkin kehilangan kendali dalam situasi tersebut. Kecemasan adalah gangguan alam perasaan yang ditandai dengan perasaan ketakutan dan kekuatiran yang mendalam dan berkelanjutan, tidak mengalami gangguan dalam menilai realitas, kepribadian masih utuh, perilaku dapat terganggu tetapi masih dalam batas-batas normal (Hawari, 2001).

Untuk mengatasi masalah kecemasan tersebut, tidur merupakan salah satu kebutuhan yang sangat penting pada pasien postoperasi untuk menurunkan kecemasannya. Proses biokimia dan biofisika tubuh manusia mempunyai irama dengan puncak fungsi atau aktifitas yang terjadi dengan pola yang konsisten dalam siklus sehari-hari. Bila irama ini terganggu seperti gangguan pola tidur pada pasien post operasi dapat mempengaruhi proses biokimia dan proses biofisika yang dapat menyebabkan penyimpangan dari norma kehidupan (Gunawan, 2013).

Kecemasan merupakan respon emosional dengan bermacam perasaan tidak menyenangkan yang ditimbulkan oleh hal yang tidak pasti atau objek yang tidak jelas. Respon yang muncul dari kecemasan bermacam-macam, mulai dari cemas kehilangan, ketakutan yang tidak beralasan, hingga perilaku yang berbeda. Perubahan dan tantangan timbul demikian cepat sehingga penyesuaian diri individu lebih sering mengalami ketidak seimbangan yang membuatnya cemas, sedih atau gelisah dan tidak bisa tidur, yang dipicu oleh ketakutan (Stuart \& Sundeen, 2008).

Dari hasil survey awal yang dilakukan oleh peneliti yang dilakukan di kelurahan pasar baru kec. Sei tualang raso pada ibu tentang kunjungan imunisasi balita dengan kecemasan diposyandu. Dari 10 orang ibu terdapat 7 orang ibu yang merasa cemas saat imunisasi di posyandu karena tidak mengerti tentang apa Imunisasi dasar sedangkan 3 orang ibu mengerti tentang imunisasi dasar. Tujuan dari penelitian untuk mengetahui lebih jauh tentang "Hubungan Pengetahuan Ibu Tentang Imunisasi Dasar Dengan Kecemasan di Posyandu Kelurahan Pasar Baru Kecamatan Sei Tualang Raso Tahun 2018”.

\section{RESEARCH METHOD}

Desain penelitian yang digunakan dalam penelitian ini adalah deskriptif korelasi. Lokasi penelitian ini dilaksanakan di Posyandu Kelurahan Pasar Baru Kecamatan Sei Tualang Raso. Penelitian dilakukan selama 5 bulan terhitung mulai dari Oktober 2018 sampai Februari 2019. Populasi dalam penelitian ini adalah seluruh ibu yang memiliki balita yang ada di Kelurahan Pasar Baru Kec. Sei Tualang Raso dengan jumlah populasi 36 orang. Teknik Pengambilan sampel dengan Total sampling. Analisa data dilakukan dengan univariat dan bivariat dengan menggunakan uji chi square.

\section{RESULTS AND ANALYSIS}

\subsection{Hasil}

Tabel 1. Distribusi Responden Berdasarkan Karakteristik Data Demografi Di Posyandu Kelurahan Pasar

Baru Kec. Sei Tualang Raso Tahun 2018

\begin{tabular}{|c|c|c|c|}
\hline No & Data Demografi & Frekuensi & Persentase $(\%)$ \\
\hline \multirow[t]{5}{*}{1} & Umur & & \\
\hline & 20-25 tahun & 18 & $50 \%$ \\
\hline & 26-30 tahun & 10 & $28 \%$ \\
\hline & $>30$ tahun & 8 & $22 \%$ \\
\hline & Jumlah & 36 & $100 \%$ \\
\hline \multirow[t]{5}{*}{2} & Pendidikan & & \\
\hline & SD & 17 & $47 \%$ \\
\hline & SMP & 10 & $28 \%$ \\
\hline & SMA & 9 & $25 \%$ \\
\hline & Jumlah & 36 & $100 \%$ \\
\hline \multirow[t]{5}{*}{4} & Sumber informasi & & \\
\hline & Media elektronik & 12 & $33 \%$ \\
\hline & Media cetak & 9 & $25 \%$ \\
\hline & Tenaga medis & 15 & $41 \%$ \\
\hline & Jumlah & 36 & $100 \%$ \\
\hline
\end{tabular}


Berdasarkan Data demografi responden mayoritas berusia 20-25 tahun sebanyak 18 orang (50\%), berpendidikan mayoritas SD sebanyak 17 orang (47\%) serta sumber informasi yang didapat berasal dari Tenaga Kesehatan sebanyak 15 (41\%).

Tabel 2. Pengetahuan Ibu di Posyandu Kelurahan Pasar Baru Kec. Sei Tualang Raso Tahun 2018

\begin{tabular}{clcc}
\hline No & Pengetahuan & F & Persentase \\
\hline 1 & Baik & 9 & $25 \%$ \\
\hline 2 & Cukup & 12 & $33 \%$ \\
\hline 3 & Kurang & 15 & $42 \%$ \\
\hline & Jumlah & $\mathbf{3 6}$ & $\mathbf{1 0 0} \%$ \\
\hline
\end{tabular}

Berdasarkan data diketahui bahwa mayoritas responden Pengetahuan Kurang sebanyak 15 orang $(42 \%)$.

Tabel 3. Distribusi Frekuensi Imunisasi Dasar Dengan Kecemasan Di Posyandu Kelurahan Pasar Baru Tahun 2018

\begin{tabular}{clcc}
\hline No & Kecemasan & F & Persentase \\
\hline 1 & Ringan & 15 & $42 \%$ \\
\hline 2 & Sedang & 21 & $58 \%$ \\
\hline & Jumlah & $\mathbf{3 6}$ & $\mathbf{1 0 0} \%$ \\
\hline
\end{tabular}

Berdasarkan data diketahui bahwa Frekuensi Imunisasi Dasar Dengan Kecemasan sebanyak 21 orang $(58 \%)$.

Tabel 4. Distribusi Frekuensi Hubungan Pengetahuan Ibu Tentang Imunisasi Dasar Dengan Kecemasan Di Posyandu Kelurahan Pasar Baru Kecamatan Sei Tualang Raso Tahun 2018

\begin{tabular}{|c|c|c|c|c|c|c|c|}
\hline \multirow[t]{2}{*}{ No } & \multirow[t]{2}{*}{ Pengetahuan } & \multicolumn{2}{|c|}{ Kecemasan } & \multirow[t]{2}{*}{ Total } & \multirow[t]{2}{*}{$\%$} & \multirow[t]{2}{*}{$\mathrm{X} 2$} & \multirow[t]{2}{*}{ P Value } \\
\hline & & Pernah & Tidak Pernah & & & & \\
\hline 1 & Baik & 5 & 4 & 9 & $25 \%$ & 0,028 & 0,05 \\
\hline 2 & Cukup & 7 & 5 & 12 & $34 \%$ & & \\
\hline 3 & Kurang & 9 & 6 & 15 & $41 \%$ & & \\
\hline & Jumlah & 21 & 15 & 36 & $100 \%$ & & \\
\hline
\end{tabular}

Berdasarkan data dapat dilihat Pengetahuan kurang sebanyak 15 orang (42\%) Kecemasan Sedang sebanyak 21 orang $(58 \%)$ dan Pengetahuan Baik sebanyak 9 orang $(25 \%)$ terdapat 15 orang Kecemasan Sedang (42\%). Berdasarkan uji chi-square diperoleh nilai signifikan p value $(0,028)<(0,05)$ ada hubungan yang signifikan antara Hubungan Pengetahuan Ibu Tentang Imunisasi Dasar Dengan Kecemasan Di Posyandu Kelurahan Pasar Baru Kecamatan Sei Tualang Raso Tahun 2018.

\subsection{Pembahasan}

Berdasarkan hasil penelitian diketahui bahwa mayoritas responden Pengetahuan kurang dan Imunisasi Dasar Dengan Kecemasan sedang. Berdasarkan data demografi responden mayoritas berpendidikan SD. Menurut (Notoatmodjo, 2010) pendidikan adalah upaya persuasi atau pembelajaran kepada masyarakat, agar masyarakat mau melakukan tindakan-tindakan (praktik) untuk memelihara (mengatasi masalah- masalah), dan meningkatkan kesehatannya. Perubahan atau tindakan pemeliharaan dan peningkatan kesehatan yang dihasilkan oleh pendidikan kesehatan ini didasarkan kepada pengetahuan dan kesadarannya melalui proses pembelajaran, sehingga perilaku tersebut diharapkan akan berlangsung lama (long lasting) dan menetap (langgeng), karena didasari oleh kesadaran.

(Astama, 2012) dalam penelitiannya menyebutkan bahwa dengan pemberian pendidikan informasi melalui media yang bervariasi membantu meningkatkan pengetahuan masyarakat sehingga masyarakat mau mengubah untuk mengubah perilaku menjadi lebih baik.

Tingkat pendidikan juga sangat berpengaruh terhadap pengetahuan ibu dalam pembentukan pola asuh balita. Penelitian yang dilakukan oleh (Rahma dan Prabandari, 2012) menunjukkan bahwa semakin tinggi pendidikan seseorang, maka semakin baik pula pola asuh yang diterapkan.

Selain pendidikan, pengalaman juga merupakan faktor yang mempengaruhi pengetahuan seseorang (Notoatmodjo, 2012). Pengalaman dapat diperoleh dari pengalaman sendiri maupun orang lain. Pengalaman yang sudah diperoleh dapat memperluas pengetahuan seseorang sedangkan pendidikan dapat membawa wawasan atau pengetahuan seseorang yang akan mempengaruhi dalam perilakunya. Secara umum, seseorang yang berpendidikan lebih tinggi akan mempunyai pengetahuan yang lebih luas dibandingkan dengan seseorang yang tingkat pendidikannya lebih rendah.

Berdasarkan hasil penelitian diketahui bahwa mayoritas responden dengan Kecemasan Sedang Kecemasan Ibu tentang Imunisasi Dasar. Imunisasi adalah suatu cara untuk menimbulkan / meningkatkan kekebalan seseorang secara aktif terhadap suatu penyakit, sehingga bila kelak ia terpapar dengan penyakit tersebut tidak akan sakit atau sakit ringan. Pengertian dari imunisasi dasar adalah pemberian imunisasi awal untuk mencapai kadar kekebalan diatas ambang perlindungan. Kelengkapan imunisasi dasar terutama ditunjukan pada bayi usia 1 tahun. Jika kekebalan seseorang terhadap penyakit tertentu diperoleh karena 
pernah menderita penyakit spesifik atau telah mendapatkan suntikan vaksin/pemberian vaksin spesifik maka ia dapat disebut telah mendapatkan imunisasi (Lisnawati, 2011).

Secara umum tujuan imunisasi adalah menurunkan angka kesakitan, kecacatan dan kematian akibat penyakit yang dapat dicegah dengan imunisasi (PD31). Sesuai dengan kesepakatan Internasional (Global Commitment) yang ikut disepakati pemerintah Indonesia, maka program imunisasi adalah: Tercapainya target Universal Child Immunization (UCI) yaitu cakupan imunisasi lengkap minimal 80\% secara merata pada bayi di 100\% desa/kelurahan setiap tahunnya. Tercapainya Eliminasi Tetanus Maternal dan Neonatal, Eradiksi polio. Tercapainya rediksi campak, Imunisasi dasar lengkap adalah imunisasi rutin program yang diberikan pada bayi usia dibawah 1 tahun meliputi: Hepatitis B dini, 1 kali (usia 0-7 hari), BCG, 1 kali (usia 1 bulan), DPT-HB, 3 kali (usia 2-4 bulan), Polio, 4 kali (usia 9 bulan), Campak, 1 kali (usia 9 bulan) Pemberian imunisasi tersebut bisa di Posyandu, Rumah Sakit, Rumah Bersalin, maupun Dokter/ Bidan Praktek (Ranuh et.al, 2011).

Dari hasil uji statistik menunjukan bahwa Pengetahuan berhubungan dengan Kecemasan Ibu Dengan Imunisasi Dasar. Semakin tinggi pendidikan semakin baik pula tingkat pengetahuan. Hal ini dapat dibuktikan dengan hasil penelitian yang ditunjukan oleh tabel demografi yaitu umur responden yang paling banyak adalah rata-rata umur 20-25 tahun. Sedangkan tingkat pendidikan yang paling banyak adalah tingkat pendidikan tingkat pendidikan Sekolah SD yaitu sebanyak 17 orang (47\%) yang menunjukan tingkat pengetahuan yang Kurang.

Asumsi peneliti dalam penelitian ini adalah semakin baik tingkat pengetahuan masyarakat semakin baik kecemasan ibu tentang imunisasi dasar. (Notoatmodjo, 2013) mengemukakan bahwa Pengetahuan dipengaruhi oleh faktor Umur, Pengalaman dan Pendidikan. Semakin cukup umur maka tingkat kekuatan dan kematangan seseorang akan lebih matang dalam berpikir. Kemudian pendidikan berarti bimbingan yang di berikan oleh seseorang per kembangan orang lain menuju kearah suatu cita-cita tertentu.

\section{CONCLUSION}

Dari hasil penelitian dan pembahasan, maka dapat diambil kesimpulan sebagai berikut:

1. Pengetahuan Ibu Tentang Imunisasi Dasar Di Posyandu Kelurahan Pasar Baru yaitu Kurang.

2. Kecemasan Ibu Tentang Imunisasi Dasar Di Posyandu Kelurahan Pasar Baru yaitu Sedang

3. Ada hubungan yang signifikan antara Hubungan Pengetahuan Ibu Tentang Imunisasi Dasar Dengan Kecemasan Di Posyandu Kelurahan Pasar Baru Kecamatan Sei Tualang Raso Tahun 2018.

\section{REFERENCES}

Arikunto, S. 2010. Prosedur Penelitian Suatu Pendekatan Praktik. Jakarta: Rineka Cipta.

Depkes RI. 2013. Cakupan Imunisasi Yang Terdapat di Daerah Ponorogo. Diunduh pada 15 Desember 2018.

Feldman, R. 2012. Menemukan Masa Hidup. Jakarta: Salemba Humanika.

Hidayat. (010. Imunisasi. Jakarta: Salemba Medika

Indah , Ani M. dan Susilowati. 2016. Hubungan Antara Tingkat Pengetahuan Ibu Tentang Imunisasi Polio dengan Tingkat Kecemasan Pasca Imunisasi Polio pada Anaknya di Posyandu Margasari Tasikmalaya Tahun 2007. Jurnal Kesehatan Surya Medika Yogyakarta. Available online: http://www.skripsistikes.wordpress.comdiakses pada tanggal 14 November 2018.

Lisnawati. 2011. Buku Ajar Cakupan Imunisasi. Jakarta: EGC.

Stuart \& Sundeen. 2008. Tingkat Kecemasan. Jakarta: Salemba Medika.

Rizani, A., Muhammad Hakimi, Djauhar Ismail. 2012. Hubungan Pengetahuan, Sikap dan Perilaku Ibu dalam Pemberian Imunisasi Hepatitis B 0-7 Hari di Kota Banjarmasin. Jurnal Berita Kedokteran Masyarakat. Volume 25, Nomor 1, November 2018.

Ranuh I. G. N, Hariyono Suyitno, Hadinegoro, Soedjatmiko. 2008. Buku Imunisasi di Indonesia. Jakarta: Satgas Imunisasi IDAI.

Notoatmodjo, S. 2010. Metodologi Penelitian Kesehatan. Jakarta: Rineka Cipta.

Saebani. 2008. Metode Penelitian. Bandung: Pustaka Setia.

Santrock, John.W. 2011. Perkembangan Masa Hidup Jilid 2. Jakarta: Erlangga.

Tecyya, Umar. 2014. Macam-Macam Imunisasi. Jakarta: Rineka Cipta dan Depdiknas. 


\section{BIOGRAPHIES OF AUTHORS}

\begin{tabular}{|l|l|}
\hline & $\begin{array}{l}\text { Sumiatik, Gelar D-III Kebidanan diperoleh dari Akademi Kebidanan Politekes Medan, } \\
\text { Jurusan Kebidanan pada tahun 2000. Gelar Sarjana diperoleh dari Universitas } \\
\text { Sumatera Utara, Jurusan D-IV Bidan Pendidik tahun 2002. Magister Kesehatan } \\
\text { diperoleh dari Universitas Sumatera Utara, Jurusan Kesehatan Reproduksi pada tahun } \\
\text { 2013. Saat ini aktif sebagai dosen tetap di Prodi D-III Kebidanan Universitas Haji } \\
\text { Sumatera Utara. }\end{array}$ \\
\hline & $\begin{array}{l}\text { Lolita Nugraeny, Gelar D-III Kebidanan diperoleh dari Akademi Kebidanan Politekes } \\
\text { Medan, Jurusan Kebidanan pada tahun 2000. Gelar Sarjana diperoleh dari Universitas } \\
\text { Sumatera Utara, Jurusan D-IV Bidan Pendidik tahun 2002. Magister Kesehatan } \\
\text { diperoleh dari Universitas Padjajaran Bandung, Jurusan Magister Kebidanan pada } \\
\text { tahun 2009. Saat ini aktif sebagai dosen tetap di Prodi Sarjana Terapan Kebidanan } \\
\text { Universitas Haji Sumatera Utara. }\end{array}$ \\
\hline
\end{tabular}

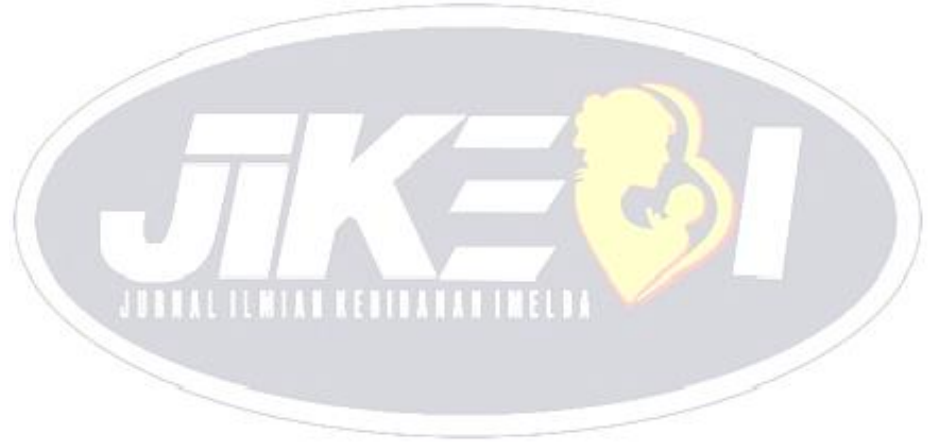

